\title{
Trazas y escrituras ${ }^{1}$
}

Traces and writings

\author{
Margoth Guzmán Munar \\ Docente Universidad Distrital \\ Francisco José de Caldas \\ mguzmanm@udistrital.edu.co
}

\section{Resumen}

Este artículo es una reflexión en torno a la escritura en diferentes escenarios de la geografía colombiana, donde se desarrollaron experiencias pedagógicas y cotidianas con maestros en contextos indígenas y campesinos en escuelas rurales; experiencias que permitieron entrever otras formas escriturales a través de las trazas, y posibilitaron metodologías diferentes para desarrollar escrituras creativas en el interior de una dinámica cultural con lógicas diferentes al mundo occidental. Desde allí se intentó sensibilizar y estrechar lazos entre el pensamiento tradicional y el contemporáneo, puesto que ser escritor significa interpretar y construir vivencias y no únicamente aquellas impuestas, sino que nos pone en relación con las ideas, sensaciones, expresiones, manifestaciones y aspectos culturales configurados a través de amplios canales comunicativos que permiten el acceso al conocimiento.

\begin{abstract}
This article is a reflection about writing in different scenarios of Colombian geography, where pedagogic and daily experiences were developed with teachers in indigenous and peasant contexts in rural schools; experiences that allowed to glimpse other writings forms through traces, to enable different methodologies to develop creative writings within a cultural dynamic with different logics to the western world. From there we tried to sensitize and strengthen ties between traditional and contemporary thought, because be a writer means interpreting and building experiences and not only those imposed, but puts us in relation with ideas, sensations, expressions, manifestations and cultural conformations through broad communication channels that allow access to knowledge.
\end{abstract}

Palabras clave: Trazas, escrituras, cultura, pedagogía, conocimiento.

${ }^{1}$ Recibido: 27/07/2018 Evaluado: 29/07/2018 Aceptado: 07/09/2018 
Keywords: Traces, writings, culture, pedagogy, knowledge.

“La escritura es la pintura de la voz; mientras más se parece mejor es"

Voltaire

\section{Introducción}

Es grato para mi presentar estas experiencias propias y no propias, que se desarrollaron a lo largo de varias jornadas en algunas comunidades indígenas, con la intención de connotar otras escrituras a través de trazos y trazas que conforman caprichosamente con la naturaleza, el hombre u otros fenómenos, con una simbología contenida en sus sistemas, estructuras y pensamientos que van en algunos casos más allá de lo cotidiano y brindan elementos básicos para desarrollar escrituras en el aula y fuera de ella.

La cultura occidental en su tradición hegemónica ha considerado a las comunidades amerindias como ágrafas o "sociedades sin escritura". No obstante, las investigaciones etnológicas contemporáneas han constatado que estas sociedades poseen un acervo cultural pletórico de escrituras, grafismos y trazas que no pasan por la escritura alfabética. Puesto que en el estudio de estas trazas escriturales se inscriben sus cosmogonías, calendarios ecológicos, calendarios agrícolas, trazos en sus rostros, en la tierra. "Las llamadas sociedades primitivas son orales, no porque carezcan de grafismos, sino al contrario, porque el grafismo en ellas es independiente de la voz y marca sobre los cuerpos signos que responden a la voz, que reaccionan ante la voz pero son autónomos y no se ajustan a ella" (Leroi 1971)

Para Paulo Freire "...la lectura de la realidad siempre precede a la lectura de la palabra (escrita alfabéticamente) y más aún, no es posible lograr una lectura crítica sino la relacionamos con el contexto. ...la palabra implica una continua lectura de la realidad que está siempre presente; incluso la palabra hablada fluye de la lectura de la realidad "...y no se crea que aprender estas escrituras es sencillo, son centenares de horas de observación y análisis del mundo lo que finalmente nos permite lograrla. Implica dedicación y esmero" (Freire, 2001, 149). Por ello, esta reflexión pretende sensibilizar y estrechar lazos entre lo tradicional y lo contemporáneo, es decir, entretejer las conformaciones culturales a través de amplios canales comunicativos que permitan el acceso al conocimiento y el intercambio de saberes. (Ver figura 1)

Lanzar tramas que se anudan a otras urdimbres para conformar tonos armónicos de texturas, formas, color, materia y función. Puesto que ser lectoescritor, significa interpretar, analizar y proponer todas las experiencias de la lectura de la vida y no únicamente aquella que nos pone en relación con el lenguaje alfabético (Mariño, 1988,6). Así como el pescador conoce el movimiento de las aguas del rio y del mar y les permite adentrase días y noches en sus entrañas, así comulga el hombre con la naturaleza, no tiene tanta parafernalia, y con su palo se entrega a la diaria labor con mucha familiaridad. Y cuando esta mareado, él lo lee y dice: 
No se puede entrar al mar hoy es bravo o picado, y son lectura que han aprendido a través de la continua vivencia y su relación con este. (Figura 2.)

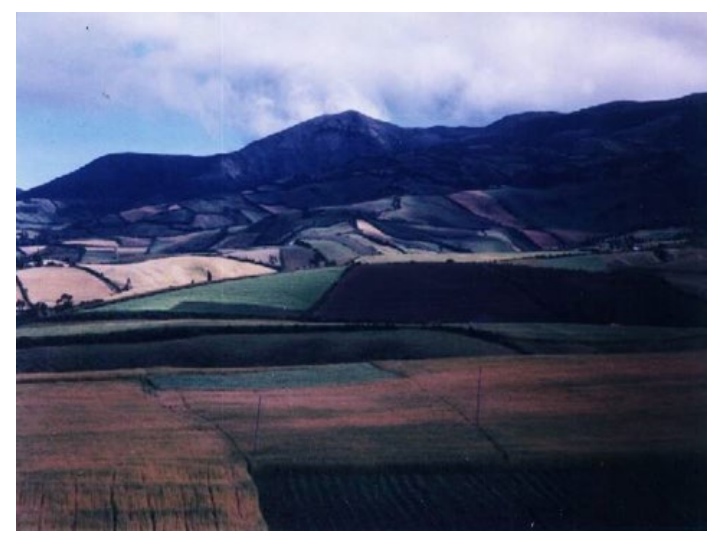

Figura 1. Retazos de paisaje andino.

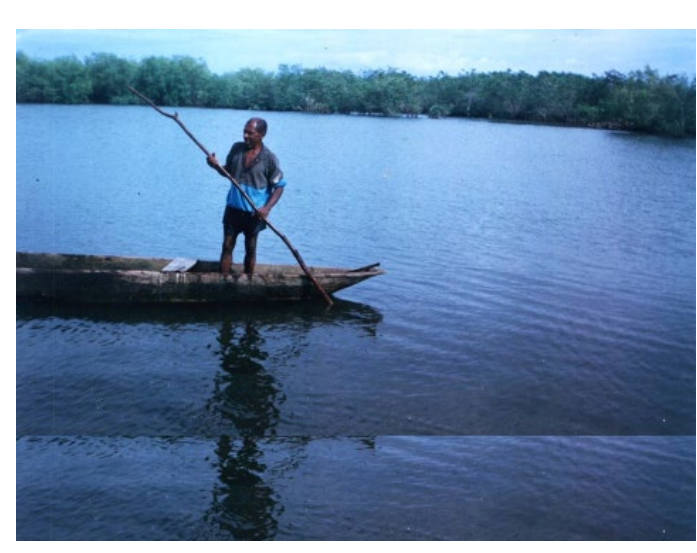

Figura 2. Lectura del mar.

\section{Antecedentes}

En las comunidades amerindias los abuelos y amautas o sabedores manifestaban que “... leer y escribir es una forma de estar en el mundo; esa forma se llama saber. Pero ¿Cómo inciden las trazas y escrituras en los contextos escolares amerindios para desarrollar procesos creativos? El develar los grafismos, las trazas, las escrituras implica abrir espacios de comunicación para articular a las sociedades étnicas con la sociedad hegemónica o viceversa $\mathrm{y}$ de esta manera apropiar, adaptar y adoptar conocimientos que fortalezcan la resignificación del pensamiento amerindio (ver figura 3). Puesto que esta actividad requiere, además de la convivencia, pasar por la sociolingüística, la semiolingüística, la antropología cultural, la etnohistoria, la etnobotánica entre otras disciplinas.

Otro de los aspectos culturales y representativos del pueblo Inga (Putumayo) es el arte como una manifestación que recoge las formas de vida y pensamiento de una cultura, se recopila aquí una serie de diseños-símbolos, propios del arte Inga. El tejido del Chumbe, elaborado por las mujeres de la comunidad; constituye la expresión del arte más importante. (Véase figuras 3, y 4) Las maestras de tejido plasman en sus trabajos una serie de diseños relacionados con la historia y las vivencias del pueblo Inga. El "Chumbe" (faja utilizada por las mujeres lnga en el vestido diario) supone una historia contada mediante diseños-símbolos.

En un chumbe se pueden encontrar simbologías relacionadas con la vida, la muerte, la familia, la naturaleza y los objetos vistos y utilizados en las vivencias diarias. Dentro del arte lnga, el "Uigsa" (estómago) simbolizado mediante la figura geométrica del rombo (abstracción de la conformación anatómica del vientre) constituye el elemento principal de donde parten los demás diseños. Además considerado como el espacio primordial donde se inicia la vida, espacio de convivencia de los hombres. (El mundo con sus cuatro puntos cardinales) espacio de conformación familiar y cuando se desintegra es también el fin de la vida misma. 


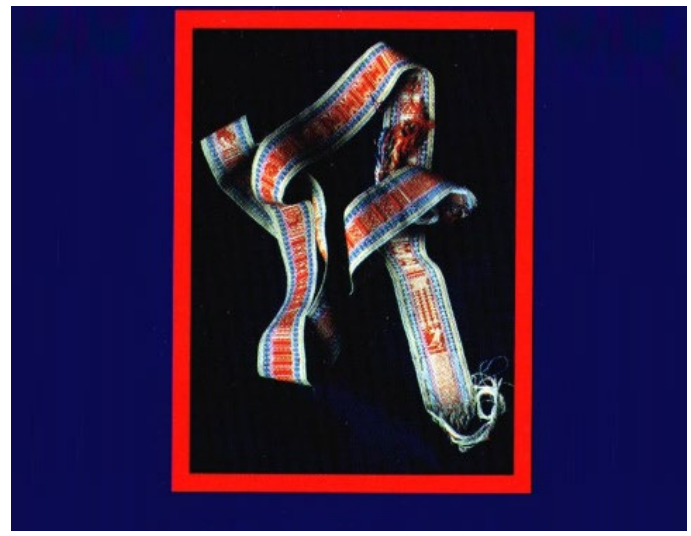

Figura 3. El Chumbe.

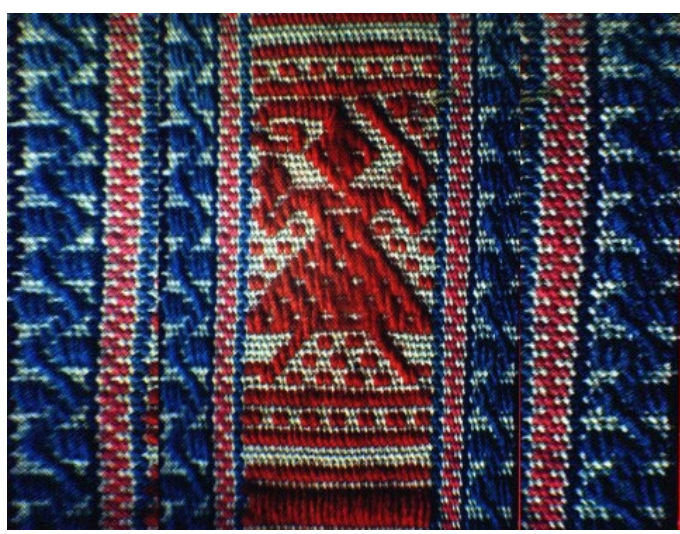

Figura 4. Tejido de chumbe.

La utilización del Chumbe es horizontal (alrededor del vientre de la mujer) y su lectura vertical, porque es así como las maestras en el tejido van escribiendo su pensamiento, el lenguaje utilizado es metafórico "Vientre con flor amarilla" es igual a mujer embarazada, es igual a mujer tuvo un hijo, "vientre estómago de volverse" es igual a familia (ciclo infinito de la procreación), etc. El rombo, representa la matriz principal, de donde a partir de su diversificación estructural, los conceptos y diseños pueden ser infinitos.

También se representan los espacios relacionados con la forma de percibir el mundo que tienen las mujeres dedicadas al arte del tejido, en especial, las que tienen que ver con la espiritualidad del pensamiento humano, lugar en que comienza, lugar de día, lugar de noche, lugar espiritual, lugar huérfano..., son parte del lenguaje utilizado a diario por las tejedoras.

\section{Metodología}

Desde la etnografía, se gestó la convivencia con las comunidades que, de una u otra manera, posibilitaron conocer sus mundos y comprenderlos, pues se consideró, que el haber compartido dos años en trabajo escolar con niños, niñas y comunidad en el internado indígena en el departamento del Guaviare, y las visitas a los abuelos y taitas de 1998 - 2005 en comunidades y escuelas de la amazonia, al sur de Colombia, lo que generó una serie de interrogantes que van desde el quehacer pedagógico hasta la participación de rituales. Lo cual conllevó a un trabajo de análisis de sus territorios, cultivos, y otras formas de cultura espiritual, material, como sus artesanías y encontrarse con una serie de símbolos que para la visión occidental pueden pasar inadvertidos, y para ellos tienen connotaciones muy significativas. Puesto que generan procesos comunicativos y sagrados de entorno ritual consigo mismo y con la naturaleza.

Por otro lado, tuve la oportunidad de compartir un proceso de profesionalización con docentes indígenas durante dos años 1998 y 1999 en la zona Andina de Nariño, en los procesos de nivelación y actualización en área de Lengua y Comunicación con 18 resguardos en los que participaron líderes, maestros y gobernadores de cabildos. En este compartir con abuelos, hombres, mujeres niños y niñas que desplegaron todo su imaginario creativo en los que se entrelazaron, el arte, la agricultura, la tierra, el cosmos, el tiempo, el alimento, la lúdica 
o la simbología en rituales de sanación, para construir lenguajes propios, cargados de profundidad que enmarcan y reafirman su identidad cultural.

Así como analiza algunas escrituras naturales montañas, nevados, paramos, sábanas, trazos y trazas de los terrenos (ver figura 5) huellas, pinturas faciales y corporales) o espacios como la cocina, donde el fogón activa significados polifónicos. Allí alrededor la tulpa - fogón fuego. Se observó que van más allá de los simples convencionalismos, pues, cumplen funciones de calidez e intimidad familiar (calor- labor- trabajo - olor - sabor -saber) afectivas filiales (fuego - calor - vientre - alimento - maternidad - afecto -vida) el involucrarse en ellas y compartir el alimento, es compartir la vida misma, la cultura, los saberes, relatos e historias colectivas e individuales. Es decir, la tulpa no es sólo el fogón sino el lazo que liga el encuentro consigo mismo y con los otros, y cuando se es aceptado se introduce en la triada sabor - saber - cultura. (Ver figura 6)

Al calor de la tulpa se adquieren los aprendizajes relacionados con historias de tradición de la familia, sus luchas, las andanzas y el trasegar de los pueblos. Por qué les toca ir de un pueblo a otro, se comprenden las razones y se participa en las diferentes labores cotidianas del hogar.

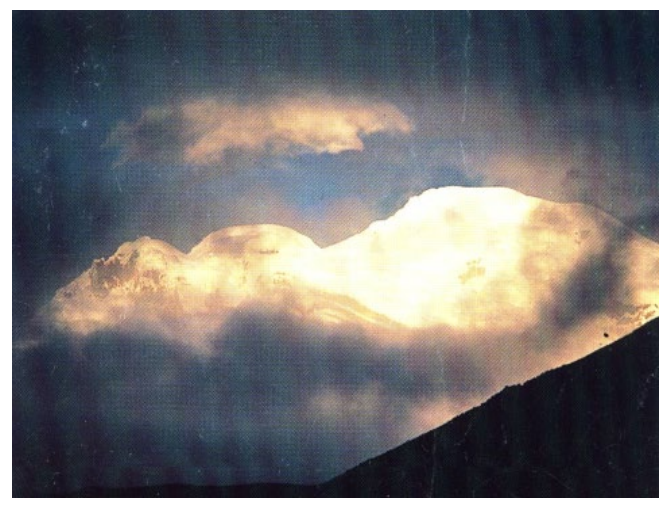

Figura 5. Escrituras naturales.

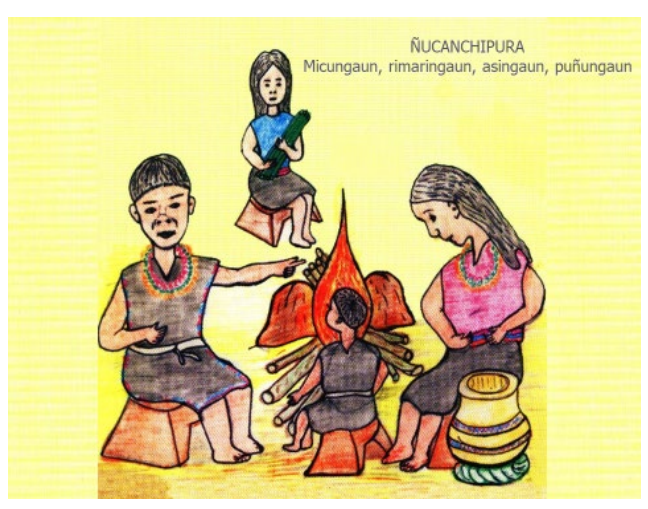

Figura 6. La tulpa.

Lo anterior, se evidencia desde la investigación etnológica contemporánea, donde las sociedades amerindias poseen un acervo cultural pleno de trazas escriturales y grafismos que han constatado la inscripción de sus cosmogonías y tradiciones estéticas. Son un componente fundamental relacionado con sus tradiciones orales. Para determinar con precisión las prácticas pedagógicas y escriturales al interior de sus hogares. En efecto, en las escuelas rurales los estudiantes de primaria, realizan itinerancias en sus salidas de campo, que les permitan reconocer su entorno y sentirlo más allá como el lugar donde vivo, sino el escenarios y lugares representativos del entorno que lo transforma con su simbología, de aquí la importancia de que los maestros conozcan y se familiarice con los espacios y establezcan alianzas con los vecinos y comunidad educativa.

Por ello son espacios de escritura... todo espacio está ligado al mundo y a la experiencia social de quien la habita, en él se escribe la memoria de la comunidad, se ubican los 
contenidos históricos y se marcan trazas (los linderos geográficos y simbólicos). También se posee recorriéndolo, observándolo, marcándolo, oliéndolo, respirándolo dejando la huella de los pies, o del arado, para construir un mapa mental de él. Es decir, marcando territorio (ver figura 7) espacio vital y físico que para ellos es vida o muerte por ser es el dador de alimento, lugar de ofrenda, de trabajo colectivo o minga. Como se observa en las "escrituras de la tierra" Representaciones que adquieren sentidos y generan lecturas pragmáticas al interior de un contexto cultural determinado, como los caminos.

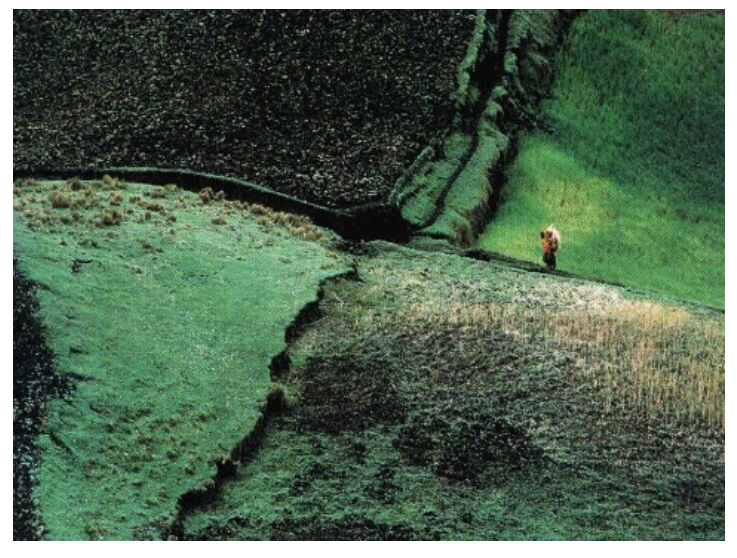

Figura 7. Trazas naturales.

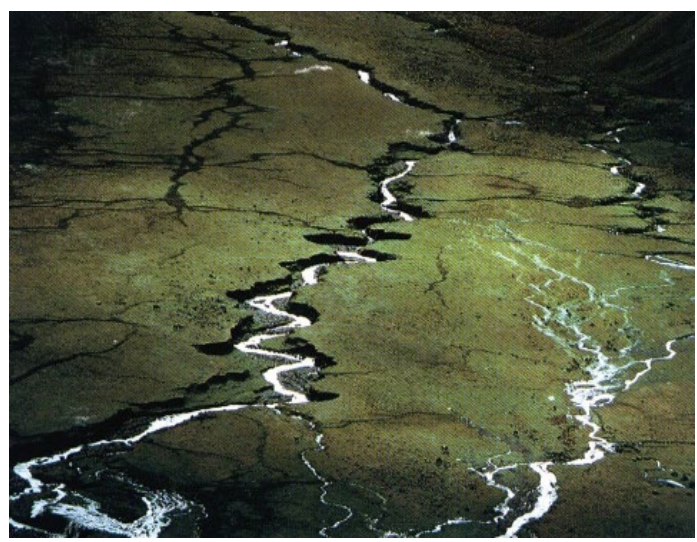

Figura 8. Caminos de lluvia.

Entre los grafismos se encuentra la percepción del cosmos a través de la lectura de las constelaciones, los rastros de la lluvia dejando sus huellas naturales (ver figura 8) en las medidas matemáticas, en las prácticas agrícolas, los calendarios ecológicos, las creencias, los ritos, los mitos, en los bailes, pinturas faciales y corporales, marcas en las rocas, en los petroglifos en los pictogramas, en el tramado de un canasto, en el tejido de mochilas.

De ahí que las comunidades amerindias llamen a la tierra "la pachamama", la cual está impregnada de innumerables significados, que se diferencian en cada cultura y hacen que la escritura expresada en grafismos que se van construyendo sin desconocer el valor cultural. En este contexto social habitan seres con dinamismo, porque allí esta su universo, su tierra, en su geografía visible e invisible, por ello valida las realidades eco - sistémicas que se presentan a través del símbolo. Es así como surge el hombre y la mujer andinos, llaneros, amazónicos o costeros.

Por ejemplo, en el hombre, con su vasta experiencia lectora de la realidad, elabora un conocimiento a partir de la relación con el universo, porque es en él y desde él que lee su naturaleza, el sistema solar, las fases de la luna; es decir, crea su propio calendario agrícola, puesto que de ello depende una buena cosecha que simboliza el futuro halagador para su familia. Las fases lunares determinan los periodos de actividad y descanso, alertan las heladas o las lluvias que borran caminos y trazan otros (ver Figura 8). El tiempo solar, dictamina la época de trazar, picar, revolver, sacudir la maleza, el deshierbe. Todo esto se hace para preparar la tierra - vientre en donde el agricultor posará la semilla. En esta actividad participan compadres y familiares en la minga en la que trabajan con voluntad, ánimo y 
alegría porque saben que la semilla muy pronto brotará y escalará hasta donde su naturaleza se lo permita.

Es de anotar, que la siembra representa para las comunidades un rito significativo, porque en ella se dimensiona el espacio, el tiempo, la cantidad, la utilidad y el beneficio. Por ello, cuando el sembrador avanza sobre el territorio para depositar las semillas, su cuerpo se mueve y se inclina con reverencia como si dejase bajo la tierra un tesoro para su familia.

Además de preparar la tierra, la alimenta, la acaricia, para depositar la semilla. En algunas comunidades del Amazonas, los hombres le cantan a la tierra preparada con instrumentos musicales elaborados con trozos de madera; la seducen e inician el ritual de la siembra, le dedican tributos al sol en gratitud de la cosecha en donde después la mujer debe hacerse cargo del cultivo, como se da en el proceso de la maternidad humana. Y en las fiestas la representación humana es a través del maíz, (Ver figura 9 y 10)

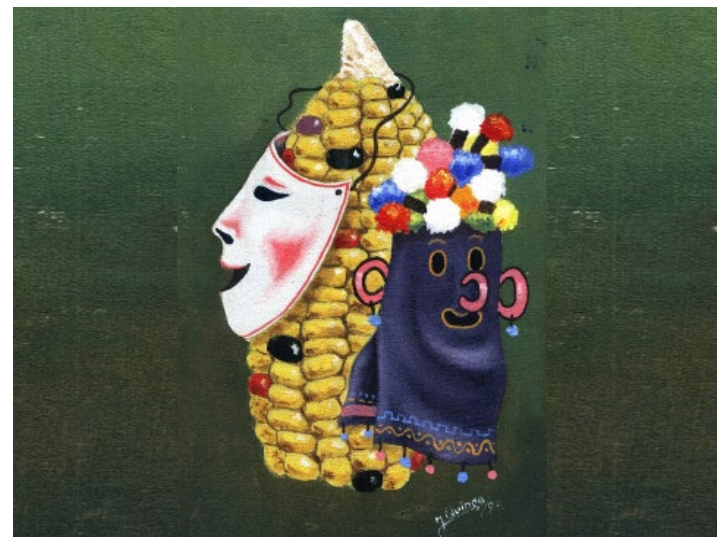

Figura 9. El hombre de maíz.

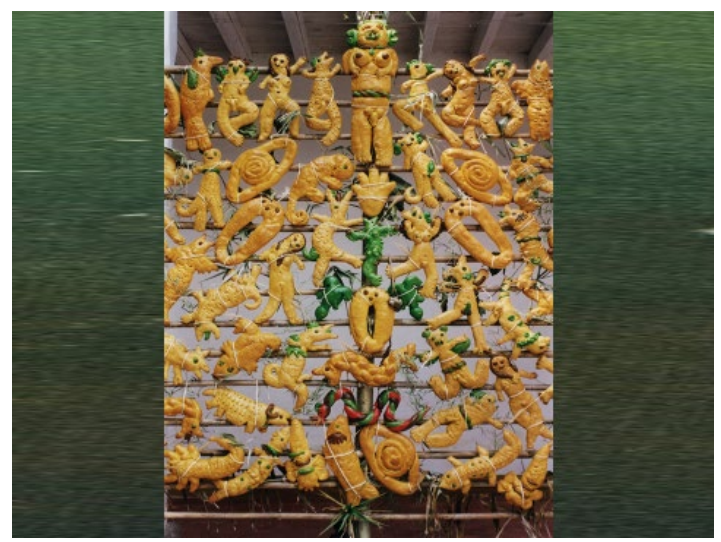

Figura 10. Rostros cósmicos de pan.

No obstante, existen lugares donde se dificulta la siembra, ya sea por el terreno o por la carencia de agua. El hombre recurre a su imaginación y crea sus propias formas de sembrar fortaleciendo su apego y gratitud hacia ella y construyen terrazas como hicieron los Incas para aprovechar los espacios fértiles y alegres. De allí se observa que al elaborar los trazos se está escribiendo (Andenes incas figura 11) y se han entrecruzado trazas que describen trazas - hileras como se observa en la (Figura 12) donde los taitas y abuelos expresaban sus cosmogonías y saberes laborales. En efecto la labor agrícola exige cuidados especiales que van desde la elección del terreno hasta la cosecha; de hecho, se desprenden una serie de rituales que terminan con las fiestas de la cosecha; los agricultores las ofrendan acompañadas de música y danza. Se inicia una matriz a partir de los trazos de cultivos y da la posibilidad de representar grafemas y figuras que crean los niños y niñas pues parten de lo sienten, ven y viven. Como los caminos, los cultivos, los ríos, generando procesos cognitivos que les permite elaborar un pensamiento más complejo y análogo en sus enseñanzas. 


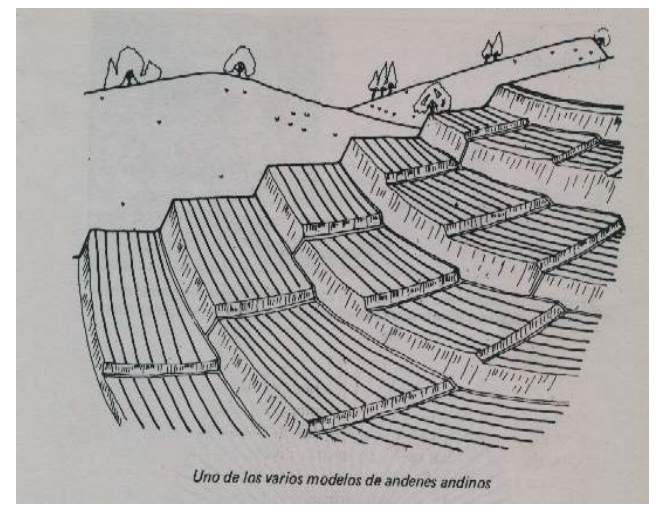

Figura 11. Andenes Incas.

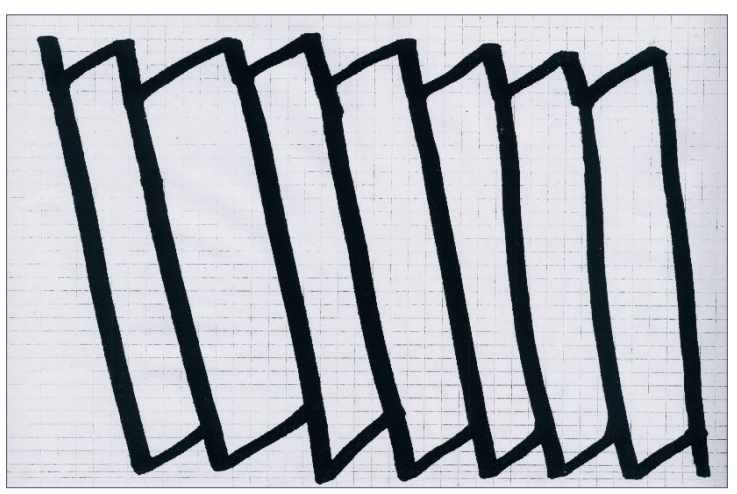

Figura 12. Trazas elaboradas en taller.

Y como en varias de estas comunidades, por tradición, los hijos le colaboran a sus padres o abuelos. Allí aprenden las actividades propias del cultivo y la relación de éste con la tierra y el universo, como se observa en los siguientes trazos y cómo a partir de aquí se generan procesos escriturales. Las cuales permiten expresar su interior a través de diversas representaciones, generando así novedosas propuestas didácticas para mejorar la escritura comprensiva que surgen de los arados. (Ver figura 13 y 14).

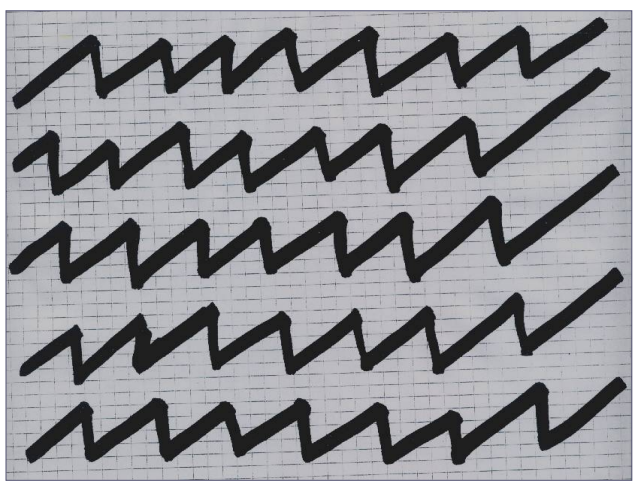

Figura 13. Trazas infantiles.

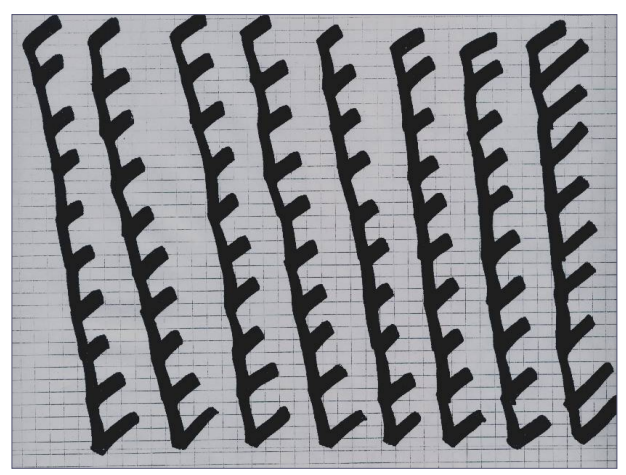

Figura 14. Hileras, grafías y rastrillo.

Son los espacios culturales los que recrean el contexto pedagógico, allí se alimenta un proyecto de educación propia para las poblaciones interculturales y campesinas a través de la socialización; socialización entendida como un proceso de incorporación del infante a la vida social, mediante la transmisión y el aprendizaje de la cultura. Los cuales se presentan en cada instante, cada momento, en cada sitio de la vida cotidiana de la comunidad.

Otra experiencia de trazas, son las pintas en los Llanos Orientales en Puerto Gaitán, Meta, la profesora Sanabria desarrolló un estudio a partir de una práctica chamánica que revela una voz diferente a la articulada, sede de una lectoescritura endógena, entendida como el leer y el escribir desde adentro que se puede interpretar como una voz de la alianza espiritual, y la 
fusión con la que se elabora la pinta se le denomina "El Kayalí", una mezcla utilizada para elaborar trazos o pintar el rostro.

De acuerdo al texto, la preparación

se inicia con el rezo o conversación con las plantas y a todo implemento que va a utilizar, luego se toman las hojas de kayalí (especie de enredadera) y se toma también parte de la corteza del árbol llamado soladillo, se hierve con las hojas frescas y coloradas del Kayalí junto con la raspadura interior de la corteza, hasta que quede el agua color marrón, luego se cuela y se pone a hervir de nuevo con manteca de guío, tortuga u otro animal para evitar que se seque. Y luego se raspa de ahí se obtiene el kayalí. Luego se pinta el rostro utilizando un palito del corazón del naranjo $(1999,174)$.

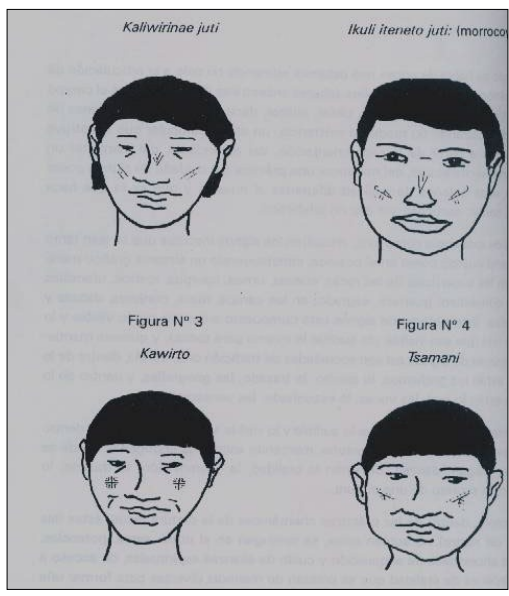

Esa pinta recibe el nombre de Juti en Sikuani. Al entrar en contacto la pinta con el rostro se inicia un llamado a sus dioses o seres aliados para cumplir su misión, ya sea para aprender labores de cacería o pesca, curar enfermedades, u obtener favores deseados; siempre y cuando esté presente el chamán (Sanabria, 175). Para los occidentales esta realidad es difícil de entender, también les es difícil comprender que allí hay lecturas y escrituras.

Dentro de las prácticas chamánicas de la pintura facial de una sola persona se marcan escrituras endógenas donde se acercan, juegan, danzan, devienen la oralidad, la cosmovi-

Figura 15. Pintas en el rostro

sión, lo trazado, las geografías, lo sagrado lo secreto de una cultura, y dentro de audible está lo real, enlazado para potenciar el orden del universo. (Ver figura 15).

Estas escrituras son "construcción, expresión, mantenimiento y extensión del pensamiento humano, a pesar de que en los contextos académicos se les excluye" (Corrales, 1998, 156). Al respecto, es necesario crear un clima favorable y productivo basado en el respeto y la valoración; que se asuma la dualidad cultura - escritura y se aborde como un fenómeno a analizar y un elemento básico para un ejercicio de enseñanza - aprendizaje, de manera que se supere los prejuicios y propenda por buscar puntos de encuentro y enriquecimiento mutuo entre unos y los otros.

En el caso de la amazonia, muchas de sus manifestaciones escritas o graficas se representan en la simbología del yagé (planta sagrada o espíritu vegetal) como la llaman los chamanes. La toma de yagé es un ritual de sanación e introspección en un contexto colectivo y simbólico. Utilizada por las comunidades Andino - Amazónicas, en Colombia es muy usual en el Departamento del Putumayo para rituales de curación y como enteógeno, es el rito 
espiritual más importante. La toma del Arnbi Uasca (Yage) trata de una bebida sagrada que se extrae de un bejuco o tallo. Según el bejuco y el lugar donde se obtiene se le nominara: Tigri Uasca, Culebra Uasca, Anti Uasca, Curi Uasca, Cielo Uasca, Cucu Uasca, Animal Uasca, Anti Uasca e incluso yage celeste o yage colibrí.

El rito del Yagé es precedido por el Sinchi runa (hombre duro) o Yacha Runa (hombre sabio), como lo llaman. Sinchi Runa, como jefe supremo del rito, luego de probar la fuerza de la bebida sagrada dispone la dosis que deben tomar los demás acompañantes. El rito dura toda una noche. Los motivos les llevan a realizar la toma del Yagé van desde una enfermedad cualquiera, hasta los males del espíritu. Sinchi Runa, durante toda la noche se canta, baila y sopla (Taki Muvurípukú), con las ramas del viento y el hijo del viento (Uaira Sacha y Uaira Uaua u ortiga) en las manos. El canto y el continuo sonido que Sinchi Runa produce con el Uaira Sacha (sonido del viento), ayudan a los presentes a irse adentrando en el mundo de los espíritus vegetales y de los ancestros. En la madrugada, Sinchi Runa le canta y le sopla a cada uno de los presentes diagnosticando y dando medicamentos según la enfermedad padecida.

\section{Discusión}

Lo anterior plantea ámbitos socioculturales que abarca la dimensión espacio -temporal en donde se da la formación infantil, en lugares como el hogar, las áreas de trabajo, la huerta, el bosque, el río, la selva, los sitios ceremoniales, la escuela. Sus protagonistas se involucran consciente o inconscientemente con todas las personas que hacen parte del mundo social y cultural de los niños en donde se observan lazos comunicativos estrechos como: madre e hijo y padre e hijo, parientes (abuela, primos y tíos), paye, chaman, amauta, anciano, sabedor, líder, y maestro.

Los contenidos del aprendizaje cultural, son un conjunto de saberes, valores y normas que conforman el patrimonio cognitivo de un pueblo, El saber histórico mítico, el saber pragmático de interacción con el medio natural y el saber social, su cosmovisión, el sentido del cosmos, el tiempo, a través de los calendarios agrícolas, ecológicos.

No obstante, de acuerdo a los planteamientos observados en diversas instituciones interculturales, las construcciones pedagógicas que se han desarrollado en las diferentes etnias, no han cumplido, ni cumplen con los roles o exigencias de las realidades culturales sino que han sido instrumento de poder económico, político, social y religioso, en favor del estado. Es una institución que se centró en generar individuos acríticos, sin posibilidad de participar y proyectarse al desarrollo social, como lo manifiesta Julia Inés Landazábal:

La escuela ha sido uno de los factores fundamentales para desequilibrar la forma de vida de los indígenas, alterando sus relaciones sociales, la concepción de autoridad que en ellas prevalecía, como su relación con la cosmovisión en unos tiempos y espacios que hacen a las culturas particulares y por lo tanto diferentes de otras. Dicho desequilibrio surge por la forma en que está estructurada la institución escolar, con unos contenidos específicos, unos agentes educativos, unos intereses y unos mecanismos que controlan el mantenimiento y reproducción de dicha estructura. 
En las comunidades indígenas, los niños tenían la oportunidad de aprender de cada una de las personas que poseían un conocimiento legítimo, en la escuela sólo del profesor; mientras en la comunidad se aprendía más por imitación, en la escuela esto se logra por imposición, parcelan los conocimientos y se desligan de la vida; en las comunidades los conceptos estaban relacionados con espacios, tiempos y con otros conceptos tal como lo manifiestan las lenguas aglutinantes. Las normas de convivencia se cambian por unas restrictivas (Landazábal, 1999, 271)

Aquí, se puede observar que al desconocerse las relaciones existentes entre el niño y familia, niño y comunidad, niño y contexto natural, se está negando toda su capacidad de aprendizaje porque sus experiencias y vivencias son más ricas, más amplias que el espacio cerrado. Además, permite la relación e interrelación que el docente no le puede brindar cuando desconoce el contexto en donde labora, no tiene claros sus roles, porque se limita a seguir pautas o esquemas y simplemente se limita a cumplir con un programa. Esto obedece a muchas razones, como la creencia de la imposición de modelos y métodos de enseñanza, carencia de capacitación, desconocimiento, marginación y discriminación de las culturas y por consiguiente, de todas las formas de expresión y comunicación y fundamentalmente de la lengua y realidades, todo esto es lenguaje.

El proceso lectoescritor en pueblos étnicos, se presenta como un proyecto de reinvención simbólica de construcción de identidad, de afirmación política. También un proyecto sagrado que involucra la realidad histórica de un pueblo. Pues el sentido del espacio vital es decir el territorio, no sólo como espacio cultural sino cósmico, un aquí y un ahora, en acontecimientos significativos como: el saber comer, saber caminar, saber hablar, saber cocinar, saber trabajar, los cuales son la expresión de un proceso acumulativo de adelantos físico motrices, valores, conocimientos y responsabilidades adquiridas por los niños.

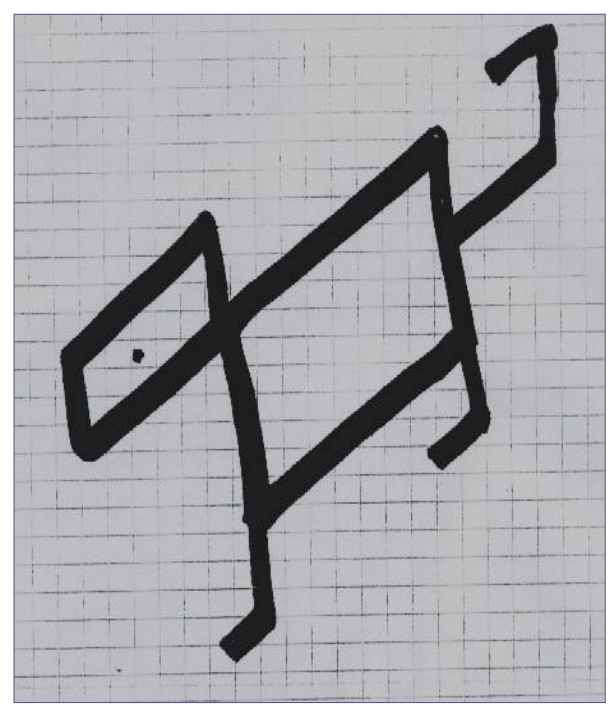

el mundo exterior.
El aprendizaje de los niños está mediado por el ciclo sensorio motor, pues son los órganos sensoriales los que permiten percibir el conjunto de estímulos provenientes del mundo exterior. Empieza a conocer el mundo con sus sentidos, su cuerpo, su espacio, los cuales son socializados por el contexto en la medida en que son transmitidos por el contexto socio cultural (Pérez, 199,33). Se inicia el niño en el mundo simbólico de la cultura, los sentidos que le circundan, los espacios por donde se moviliza la madre, el sonido de los animales, el canto de los pájaros, el sonido del viento de los árboles, del río, de la montaña de la lluvia, del fogón; mira lo que rodea su existencia, los colores, las formas (las trazas); se impregna del olor de la tierra, de las plantas. Es aquí donde establece un contacto con

Figura 16 
Por ello la etnoeducación como perspectiva socio-cultural traduce las expectativas de búsqueda de nuevos modos de expresión cultural, social y política en las comunidades indígenas. Al discutir el problema de la etnoeducación saltan al primer plano los principios de interculturalidad (MEN 1982,) y de diversidad cultural. (Bodnar, 1985)

"Cuando hablamos de interculturalidad tenemos que partir del conocimiento y del respeto por la cultura propia para estar en capacidad de conocer, valorar y criticar las otras culturas. Cuando se habla de interculturalidad, el indígena debe reconocerse como miembro de la sociedad..." Bodnar, 1985)

El trabajo de los niños y niñas de las escuelas de los resguardos facilita el desarrollo de la motricidad, puesto que el entorno lo propicia y crea los espacios para llevarlo a cabo. También se aprovecha la metodología, pues permite trabajar las más variadas representaciones como se observa (ver figura 16) con su amigo el perro, animal vital de la compañía de los niños en las escuelas.

Emilio Durkheim manifestó que "El aspecto social es el proceso por el cual la persona aprende a interiorizar en el transcurso de su vida los elementos socioculturales de su medio ambiente, los integra en la estructura de su personalidad, bajo la influencia de experiencias y agentes sociales significativos, y se adapta así al entorno sociocultural donde va a vivir" (Durkheim, 1992,27).

Nada más práctico que sentirse miembro de una sociedad cultural y explorarse así mismo. Esto es lo que hoy más que nunca hará que los niños y niñas puedan recordar ese añorado mundo de su infancia.

\section{Reflexiones finales}

Lo anterior, permite observar que las escrituras diferentes a las alfabéticas son cargadas de simbologías y sentidas y para ello se requiere aprehender a interiorizar el contexto sociocultural en el que se movilizan. Es decir, compenetrarnos con el mundo que nos rodea, lleno de sentimientos, ideas, expectativas, se está en un proceso de elaboración y adquisición de conocimientos, y es el lugar de encuentro entre culturas, pues permiten la interculturalidad, desde sus percepciones y condiciones para mantener el respeto por la diferencia.

A pesar de que las trazas y escrituras no son convenciones universales, si cumplen una función cultural $\mathrm{y}$ ritual al interior de las comunidades, puesto que, modifican considerablemente al sujeto que la ejercita. Es una tecnología del intelecto y de la comunicación. "Su práctica implica cambios en las operaciones mentales, en la inteligencia, la memoria, la imaginación, en las relaciones interpersonales, la relación con el cuerpo, con el tiempo, con el universo" (Landaburu, 1999, 119). A saber, produce un escenario que implica partir de la mente, toda la vida social. 
De ahí que se den resistencias y re - existencias, rechazos de apropiación individuales y colectivos o, al contrario deseos de apropiación racional y fantástica. Pues el problema del leer y escribir no reside en las letras sino en la comunicación y en estos tiempos de globalización que la comunicación está tan deteriorada, son una alternativa agradable para refrescar el alma y el pensamiento.

En sí, las trazas y escrituras cumplen una función no solo social, pedagógica sino también de revitalizar el lenguaje para la pervivencia de las comunidades y de nosotros. Cortázar manifestó alguna vez que "Un lectoescritor comprometido con la revolución cultural evitará seguir derramando sangre para lograr el cambio que necesita el hombre, para iniciar con buenos pasos un mundo más prometedor sino queremos dejar un cementerio o un basurero que es lo que se está convirtiendo nuestra casa la tierra"

Finalmente, las trazas y escrituras, son escenarios de encuentro donde transitan las culturas, y permiten procesos de interculturalidad, desde sus percepciones y condiciones para mantener el respeto por la diferencia. Pues, en estos momentos de incomprensión con las pluralidades, parece apropiado compartir estas experiencias y ser más tolerantes en la diversidad en relación a procesos formativos y pedagógicos.

\section{Referencias}

Bodnar, Y. (1985). Memorias $1^{\circ}$ Congreso de Etnoeducación. Bogotá: Ed. Ministerio de Educación Nacional MEN. Prodic.

Corrales, M. (1998). Reflexiones en torno a la oralidad y escritura. Primer Congreso Universitario de Etnoeducación. Riohacha: Ed. Universidad de la Guajira.

Durkheim, E. (1992). Education et Sociologie. París: ediciones Felix Alcanb.

Freire, P. (2001). La importancia de la lectura, esbozado en Boletín de la historia de la educación latinoamericana. Tunja: Ediciones el Búho.

Leroi, A. (1971). El gesto y la palabra. Traducción Felipe Carrera. Caracas: Ediciones biblioteca Universidad Central de Venezuela.

Landaburu, J. (1999). Condiciones para el desarrollo de la práctica de la escritura en las Sociedades Indígenas- Bogotá: Editores ICANH.

Landázabal, J. (1999). Etnoeducación Conceptualización y Ensayo. Bogotá: Editado por el Ministerio de Educación Nacional MEN. Prodic.

Mariño, G. (1988). Escritos sobre escritura. Bogotá: Editores Dimensión Educativa.

MEN. (1982). Programa de Formación de Etnoeducador, en Lineamientos Generales de Educación Indígena, Bogotá: Editado por el MEN. 
Pérez, L. (1999). Procesos de Socialización Infantil "Una mirada a la cultura U'wa. Bogotá: Ed. ICANH.

Sanabria, M. (1999). Juti Sicuani o la Voz de la Alianza Espiritual, publicado por VII Congreso de antropología, Culturas, Lenguas y Educación. Bogotá: Editores ICANH. 